\title{
Social cues can play a role in timing onset of the breeding season of the ewe*
}

\author{
N. L. Wayne $\dagger$, B. Malpaux $\ddagger$ and F. J. Karsch \\ Reproductive Sciences Program and Department of Physiology, The University of Michigan, \\ Ann Arbor, Michigan 48109, USA
}

\begin{abstract}
Summary. Female Suffolk sheep were pinealectomized around the vernal equinox to eliminate the major environmental input to the reproductive system (photoperiod) and then either isolated from, or maintained with, pineal-intact gonad-intact sheep. The ewes were ovariectomized and treated with constant-release oestradiol implants and reproductive state was monitored by measuring serum $\mathrm{LH}$ concentrations. Pinealectomized ewes that were isolated from the normal flock showed a $2 \frac{1}{2}$-month delay in onset of the seasonal rise in $\mathrm{LH}$ values compared with that of pineal-intact controls (18 November vs 5 September). On the other hand, pinealectomized ewes that were maintained with the flock showed an onset of the seasonal rise in LH that was not delayed. These results suggest a timekeeping role for social cues for timing onset of the breeding season in an animal that normally relies on photoperiodic signals for temporal regulation of the seasonal reproductive cycle.
\end{abstract}

Keywords: photoperiod; pineal gland; seasonal reproduction; sheep; social cues

\section{Introduction}

A common reproductive strategy amongst mammals living in seasonally fluctuating environments is the restriction of breeding activity to an optimal time of year. This helps to ensure that births normally occur at a time that both promotes maximal growth and development of the offspring and supports lactation in the mother. Photoperiod is a reliable, noise-free geophysical cue that is widely used among temperate zone mammals to synchronize seasonal reproductive activity to time of year (Thomson, 1950; Turek \& Campbell, 1979). Although photoperiod may be the best predictor of the most favourable time of year to breed, it does not inform the animal about the availability of mates in a particular locality, and thus the suitability of becoming reproductively active in a specific place at any given time. On the other hand, there is evidence that social cues emanating from conspecifics can influence the timing of reproductive function in birds (Schwab \& Lott, 1969; Cheng, 1976; Hinde \& Steel, 1978) and oestrous cyclicity and the occurrence of ovulation in a number of mammalian species (rodents: Whitten, 1956; Vandenbergh, 1969, 1977; McClintock, 1978; ungulates: Grubb \& Jewell, 1973; Martin et al., 1980; Chemineau, 1983), as well as the synchrony of menstrual cycles in human and non-human primates (McClintock, 1971; Rowell \& Dixson, 1975; Russell et al., 1980).

The present study tested the hypothesis that social cues can synchronize the onset of seasonal reproductive activity in a mammal that normally relies on photoperiod for temporal regulation of an annual rhythm of reproduction. Specifically, we determined whether social cues from gonad-intact sheep could affect the timing of seasonal reproduction in ewes that were rendered

${ }^{*}$ Reprint requests to Dr F. J. Karsch.

†Present address: Department of Biology, Gilmer Hall, University of Virginia, Charlottesville, VA 22901, USA.

$\ddagger$ Present address: INRA Station de Physiologie de la Reproduction, 37380 Nouzilly, France. 
non-responsive to photoperiodic cues. Our approach was to pinealectomize adult Suffolk ewes and either to isolate them from the flock or to maintain them with pineal-intact, gonad-intact ewes and rams. The effect on seasonal changes in reproductive neuroendocrine activity was then established.

\section{Materials and Methods}

General. Adult ewes (2-4 years of age), either purebred Suffolk or predominately Suffolk bred, were maintained at the Sheep Research Facility near Ann Arbor, MI $\left(42^{\circ} 18^{\prime} \mathrm{N}\right)$. They were maintained on pasture from late spring to mid-autumn and fed hay at other times of year. Animals had free access to mineral licks and water. All ewes were maintained outdoors before and during the course of the study.

Pinealectomy was performed by the method of Roche \& Dziuk (1969) and modified slightly as described by Dempsey et al. (1982). Completeness of pinealectomy was verified initially by visual inspection of the excised pineal gland and site of removal, and subsequently by documentation that the nocturnal rise in melatonin was eliminated (see below).

At 1-8 months before pinealectomy, all ewes were ovariectomized and implanted s.c. with one Silastic capsule packed with $3.0 \mathrm{~cm}$ oestradiol (Karsch et al., 1973). The oestradiol capsules are known to maintain a physiological concentration of serum oestradiol for a period exceeding the duration of this study (3-5 pg/ml; Legan et al., 1977). Reproductive neuroendocrine activity was assessed from serum luteinizing hormone $(\mathrm{LH})$ concentrations in blood samples $(5 \mathrm{ml})$ taken twice weekly by jugular venepuncture. Changes in LH secretion in this model reflect changes in the hypothalamic response to oestradiol negative-feedback, and this constitutes a major neuroendocrine determinant of seasonal reproduction (Legan et al., 1977; Legan \& Karsch, 1980). Rising and falling concentrations of serum LH are photoperiodically regulated and coincide with the onset and termination of breeding activity in intact ewes, respectively. These swings in serum LH are large ( $>30$-fold) and thus they provide a robust marker of the seasonal reproductive state (Legan et al., 1977). Times of elevated LH are defined as the 'neuroendocrine breeding season' (see 'Analysis of data').

Assays. Serum was obtained after blood was allowed to clot overnight at $4^{\circ} \mathrm{C}$ and stored at $-20^{\circ} \mathrm{C}$ until assayed. LH was determined in duplicate $25-200 \mu \mathrm{l}$ samples of serum and is expressed as ng NIH-LH-S12/ml, as previously described (Niswender et al., 1968, 1969; Hauger et al., 1977). The intra-assay coefficient of variation (CV) for standard sera containing $0.93 \pm 0.02$ (mean \pm s.e.m.), $2.16 \pm 0.03$ and $30.76 \pm 0.57 \mathrm{ng} / \mathrm{ml} \mathrm{LH}$ averaged $6.6 \%$. The interassay $\mathrm{CV}$ for the 3 serum pools averaged $6.5 \%$. The limit of detection (2 standard deviations from the buffer controls) averaged $0.26 \pm 0.02$ for $200 \mu \mathrm{l}$ serum. To standardize the baseline for statistical purposes, LH data below $0.44 \mathrm{ng} / \mathrm{ml}$ (upper value from the range of limit of detections in this study) were assigned this value.

To verify the completeness of pinealectomy, melatonin was determined in duplicate $200 \mu$ samples of serum ( 5 day- and 5 night-time blood samples from each ewe) using the method of English et al. (1986), modified as described by Malpaux et al. $(1987,1988)$. The intra-assay CV for standard sera containing $92 \cdot 2 \pm 4 \cdot 6$ and $427 \cdot 1 \pm 19 \cdot 2 \mathrm{pg}$ melatonin/ml averaged $9 \cdot 1 \%$. The interassay $\mathrm{CV}$ for the 2 serum pools averaged $13.4 \%$. The limit of detection was $14 \cdot 1 \pm 3 \cdot 5 \mathrm{pg} / \mathrm{ml}$ for $200 \mu \mathrm{l}$ serum. The melatonin rhythm was abolished in all pinealectomized ewes (serum melatonin was low to undetectable in the day- and night-time samples). Normal night-time values usually exceed $200 \mathrm{pg} / \mathrm{ml}$.

Experimental design. We rendered animals non-photoperiodic (via pinealectomy) to eliminate the primary external input to the reproductive system (photoperiod). This increased our chances of observing effects of social cues by eliminating potentially masking effects of photoperiod. In a preliminary study, we determined that pinealectomy in the early spring greatly altered the time of the onset of reproductive neuroendocrine activity in ewes that were isolated from gonad-intact ewes and rams (Wayne, 1988); this time of surgery was therefore chosen in the present experiment. Eleven ewes were pinealectomized within 2 weeks of the spring equinox (9 March-3 April 1987); these ewes had experienced some lengthening days and were in the early anoestrous season. Before pinealectomy, all ewes were maintained in the same pasture and paddock with unoperated rams and other ewes (ovariectomied ewes treated with oestradiol implants and intact ewes). After surgery, however, 5 of the pinealectomized ewes remained with the normal flock while the remaining 6 animals were physically isolated from rams and other ewes in a separate paddock to minimize social influences on reproductive function (animals separated by at least 280 feet). A control group of pinealintact, ovary-intact ewes $(\mathrm{N}=8)$ was maintained with the flock to monitor the timing of the natural breeding season. Serum LH concentrations were monitored in all ewes for at least 15 months beginning at the time of surgery.

Analysis of data. Rises and declines in serum LH concentrations were identified by slight modification of an algorithm that uses regression-like statistics with a moving variable-length window to detect changes in hormone concentrations (Malpaux et al., 1988; modification described in Wayne et al., 1988). This algorithm can identify 4 phases of a cycle: baseline, rise, plateau, and decline. Differences in the timing of rises and declines of LH were analysed by the Kruskal-Wallis test (analysis of variance) and the Mann-Whitney U test (two groups) (Siegel, 1956). Differences in variability between the onsets of LH rises were analysed by F-distribution (Brown \& Hollander, 1977). Values were considered significantly different if $P<0.05$.

Occasionally, we observed periods of elevated LH in the 2 pinealectomized groups; these rises were very brief in duration, sometimes lasting only a few days. We chose to distinguish these brief bouts of elevated LH from longer periods of elevated $\mathrm{LH}$, which may have greater reproductive significance. Our criterion to make this distinction was 
that LH had to be elevated for more than 34 days (duration of 2 complete oestrous cycles in intact ewes) to be considered a 'neuroendocrine breeding season'. The rationale behind this criterion was as follows. The first ovulation of the breeding season is considered to be 'silent'; it is not until the second ovulation, when a decline in progesterone concentration is followed by a sustained rise in oestradiol concentrations, that behavioural oestrus is manifest in our flock (Legan et al., 1977; Robinson \& Karsch, 1984). Therefore, the opportunity for breeding is not available until the second oestrous cycle.

\section{Results}

All results are presented in Fig. 1. In pineal-intact controls maintained with the flock, circulating LH values rose from baseline on 5 September \pm 3 days (mean \pm s.e.m.; Fig. 1a). Among pinealectomized ewes isolated from the flock, $\mathrm{LH}$ began to rise on 18 November \pm 16 days (Fig. $\mathrm{lb}$ ). This LH rise was significantly delayed $(P<0.01)$ and the timing more variable $(P<0 \cdot 05, \mathrm{~F}=19 \cdot 2)$ compared with that of the control group. The apparent elevation in LH from September through November, shown in the top portion of Fig. 1(b), is contributed solely by 1 ewe (No. 6057, see lower portion of Fig. 1b). Pinealectomized ewes maintained with the flock showed an LH rise beginning on 9 September \pm 10 days (Fig. Ic). This date was not significantly different from that of the control group, but was earlier than that of the isolated pinealectomized ewes $(P<0.02)$. The variability in timing was greater than that of the control group $(P<0.05, \mathrm{~F}=7 \cdot 3)$, but not different from that of the isolated group $(F=2 \cdot 6)$.

LH concentrations fell back to baseline in pineal-intact controls on 8 February \pm 7 days (Fig. 1a). The fall in LH was delayed $(P<0.01)$ in pinealectomized ewes maintained with the flock (26 March \pm 13 days, Fig. 1c). The decline was also delayed in 3 of the 6 pinealectomized ewes isolated from the flock; values in the other 3 ewes of this group were still elevated when the study was terminated on 28 June (Fig. 1b). As a result, LH remained elevated later into the year in pinealectomized ewes that were isolated compared with ewes that were kept with the flock $(P<0.03)$.

\section{Discussion}

The results from the present study indicate that social cues emanating from normal sheep can synchronize the onset of seasonal reproductive activity to the appropriate time of year in ewes that are not responsive to photoperiodic signals. Our findings complement observations on feral Soay sheep which suggest social cues may contribute to synchronizing reproductive onset in ewes that are capable of perceiving photoperiodic information (Grubb \& Jewell, 1973). The more variable time of the onset of the $\mathrm{LH}$ rise among our pinealectomized ewes that were both isolated from and maintained with the flock compared with that of the controls suggests that social cues provide a relatively weak time cue compared with the combination of photoperiodic and social signals.

Earlier studies have provided some suggestion for an effect of social cues in synchronizing seasonal reproductive cycles in sheep. For example, sheep that were blinded, pinealectomized or superior cervical ganglionectomized, while not responsive to photoperiodic signals, did show longterm cycles in reproduction that ultimately became desynchronized (Lincoln, 1979; Bittman et al., 1983; Legan \& Karsch, 1983; Wayne, 1988). Synchrony of these cycles was maintained, at least for a while, when blinded or pinealectomized ewes were maintained with normal ewes and rams (Clegg et al., 1964; Bittman et al., 1983). Unlike the present experiment, those previous studies were not controlled to identify effects of isolation from normal sheep, and therefore did not definitively test an effect of social cues. Lincoln et al. (1989) have shown that Soay rams that were superior cervical ganglionectomized or pinealectomized and maintained outdoors with intact rams exhibited cyclic changes in reproduction, while animals maintained indoors showed poorly defined and irregular cycles. Although this study did not directly test the role of social cues in seasonal reproductive 
N. L. Wayne et al.
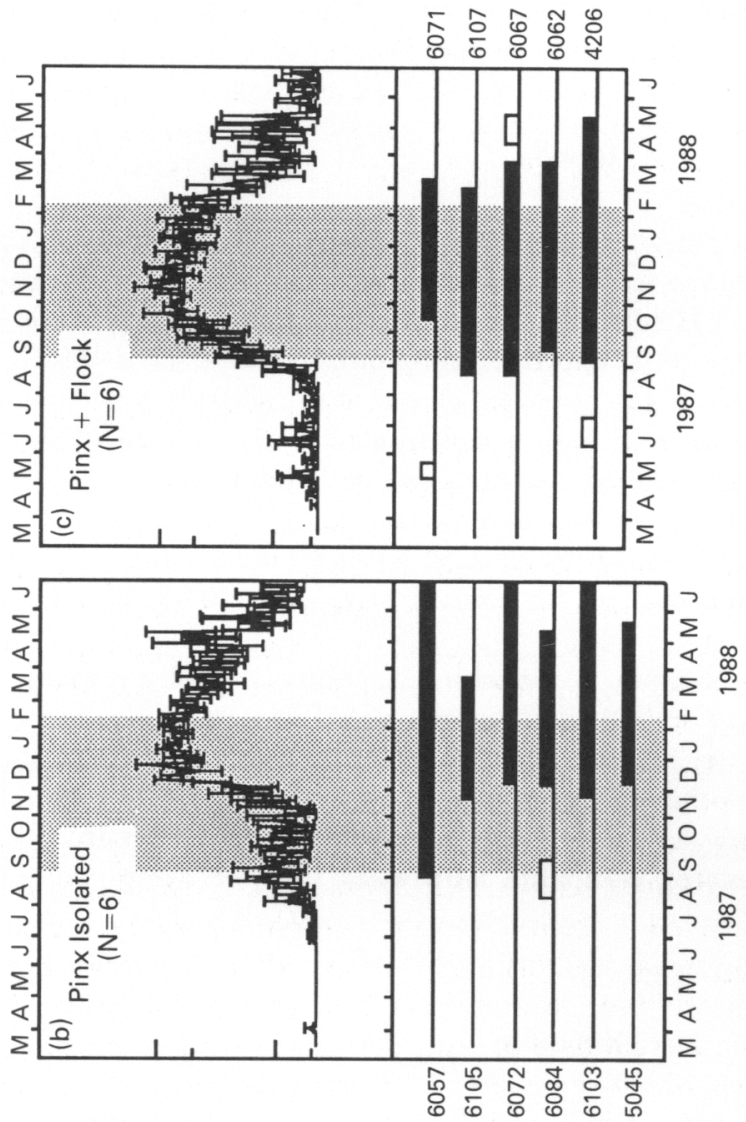

马承 舟志

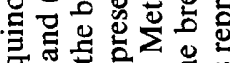
ซึ。

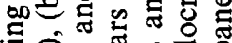

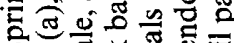

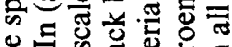

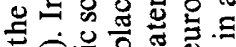

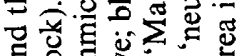

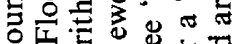

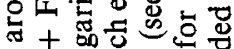

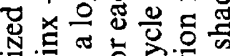

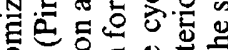
응 㯊 듬음 2.

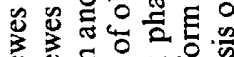

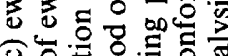

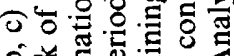

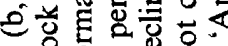

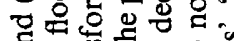

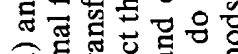

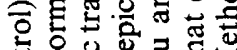
을.웜

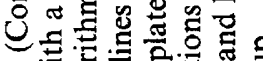
क

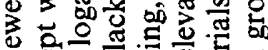

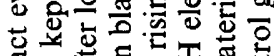

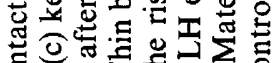

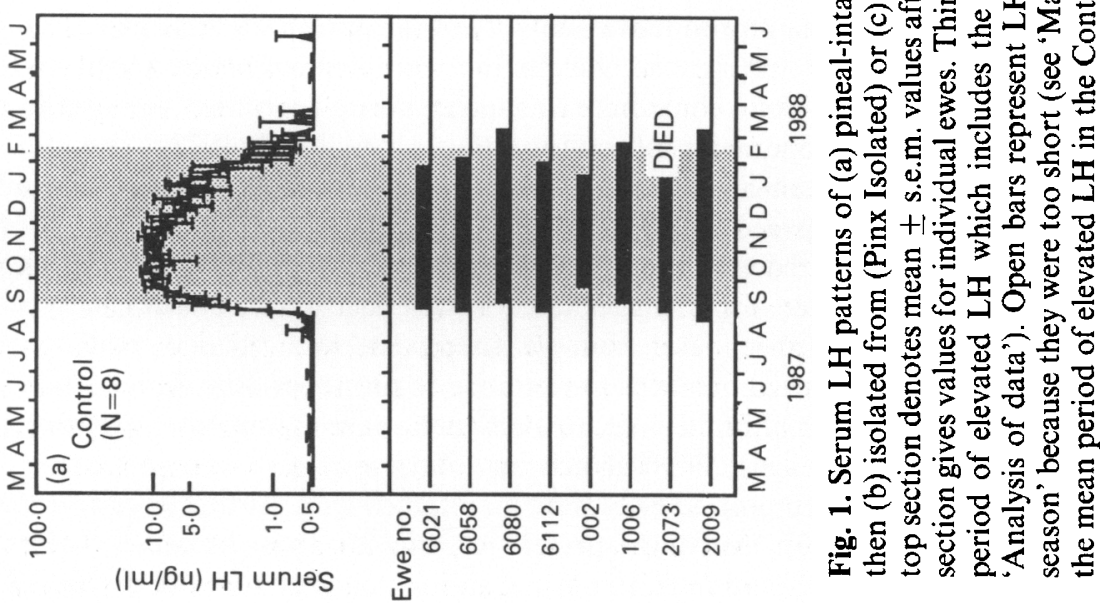


synchronization, the results strongly suggest that external factors other than photoperiod (i.e. social cues and nutrition) can influence the reproductive condition of the ram.

Our present study did not distinguish whether the social cue(s) orginated specifically from the male or the female, because the pinealectomized ewes kept with the flock were exposed to both sexes. Previous work, however, provides suggestive evidence that the ram can influence the time of seasonal changes in reproduction in the ewe: blinded ewes maintained with sighted rams and exposed to repeated 90-day alternations between artificial long and short days showed corresponding shifts in reproductive neuroendocrine activity (Legan \& Karsch, 1983). Upon removal of the ram, the reproductive shifts in these ewes no longer corresponded to the photoperiodic alternations. Although those findings are consistent with the possibility that photoperiodic information was conveyed indirectly to the blinded ewes via chronic exposure to normal rams, it is important to stress that those studies were not designed in a manner which allowed a definitive test for such an effect of the ram.

Clearly, the ram can elicit acute reproductive responses from ewes. For example, upon introduction of a ram, seasonally anoestrous ewes previously isolated from males can ovulate within $48 \mathrm{~h}$ (Oldham et al., 1979). In this case, the ram prompts an immediate increase in frequency of pulsatile LH secretion that leads to an LH surge and hence ovulation (Poindron et al., 1980; Martin et al., 1983). This acute ram effect is likely to be mediated by a chemosensory signal because wool clippings from rams stimulate $\mathrm{LH}$ secretion in anoestrous ewes isolated from rams (Signoret \& Lindsay, 1982). It may be important, however, to distinguish this acute ram effect from the social cue effect observed in our study, because the acute ram effect is short-lived and generally elicits only a single ovulation (Signoret \& Lindsay, 1982), whereas in our study the response was produced by chronic exposure to familiar animals. The social cue need not be chemosensory: auditory signals can influence the timing of reproduction in deer (McComb, 1987).

Previous studies in sheep suggest that the seasonal reproductive rhythm is generated by an endogenous process (Ducker et al., 1973; Howles et al., 1982; Bittman et al., 1983; Legan \& Karsch, 1983; Almeida \& Lincoln, 1984; Robinson \& Karsch, 1988) and that photoperiod serves to entrain this rhythm rather than act as a driving signal (Robinson \& Karsch, 1988). For instance, ewes that have been rendered non-photoperiodic via pinealectomy can show spontaneous cycles in reproductive function that are desynchronized from time of year; desynchronization can be prevented by infusion of melatonin, a hormone which serves as an internal mediator of photoperiodic information (Bittman et al., 1983; Robinson \& Karsch, 1988). The present results suggest that social cues can synchronize onset of reproductive activity to the normal time of year. The design of the present study, however, does not allow us to draw inferences as to whether social cues serve to entrain an endogenous rhythm of reproduction as does photoperiod, or whether they act as a direct driver of reproductive neuroendocrine activity.

Our study raises other questions concerning social synchronization of the seasonal reproductive cycle of the ewe. For example, while our findings identify an effect of social cues on the timing of reproductive onset, their influence on the end of the breeding season is less compelling. An effect on reproductive offset remains an open question because it was necessary to end the study without determining whether $\mathrm{LH}$ returned to baseline in all the pinealectomized ewes isolated from the flock. Moreover, the study did not address the importance of social synchronization in intact ewes that are capable of responding to photoperiod. Further studies are therefore needed to clarify our understanding of social synchronization of seasonal reproductive cycles in mammals.

We thank Mr Douglas Doop, Ms Barbara Glover, Ms Suzanne Moenter, Mr Diarmuid O'Callaghan, Mr Kirk Van Natter and Ms Celia Woodfill for technical assistance; Dr Gene Block, Dr Michael Menaker and Mr Christopher Colwell for critical evaluation of the manuscript; Mr Michael Muha and Dr Morton Brown for computer assistance and statistical analysis; the Standards and Reagents, Data Analysis and Sheep Research Core Facilities of the Center for the Study of Reproduction; and Dr J. Arendt, Dr G. D. Niswender and Dr L. E. Reichert, Jr for 
supplying assay reagents. This work was presented in preliminary form at the 1 st meeting of the Society for Research on Biological Rhythms, 1988, p. 22, and was performed in partial fulfilment of the requirements for the degree of $\mathrm{Ph}$.D. at The University of Michigan (to N.L.W.). Supported by NIH-HD-18337, P30-HD-18258, NIH-T32-HD 07048 (support of N.L.W.), the INRA of France (support of B.M.) and a grant from The University of Michigan Office of the Vice-President for Research.

\section{References}

Almeida, O.F.X. \& Lincoln, G.A. (1984) Reproductive photorefractoriness in rams and accompanying changes in the patterns of melatonin and prolactin secretion. Biol. Reprod. 30, 143-158.

Bittman, E.L., Karsch, F.J. \& Hopkins, J.W. (1983) Role of the pineal gland in ovine photoperiodism: regulation of seasonal breeding and negative feedback effects of estradiol upon luteinizing hormone secretion. Endocrinology 113, 329-336.

Brown, B.W., Jr \& Hollander, M. (1977) In Statistics: A Biomedical Introduction, pp. 234-238. John Wiley and Sons, Inc., New York.

Chemineau, P. (1983) Effect of oestrus and ovulation of exposing creole goats to the male at three times of the year. J. Reprod. Fert. 67, 65-72.

Cheng, M.F. (1976) Interaction of lighting and other environmental variables on activity of hypothalamohypophyseal-gonadal system. Nature, Lond. 263, 148-149.

Clegg, M.T., Cole, H.H. \& Ganong, W.F. (1964) The role of light in the regulation of cyclical estrous activity in sheep. USDA Misc. Publ. 1005, 96-103.

Dempsey, R.J., Hopkins, J., Bittman, E.L. \& Kindt, G.W. (1982) Total pinealectomy by an occipital parasagittal approach in sheep. Surg. Neurol. 18, 377-380.

Ducker, M.J., Bowman, J.C. \& Temple, A. (1973) The effect of constant photoperiod on the expression of oestrus in the ewe. J. Reprod. Fertil., Suppl. 19, 143-150.

English, J., Poulton, A.L., Arendt, J. \& Symons, A.M. (1986) A comparison of the efficiency of melatonin treatments in advancing oestrus in ewes. J. Reprod. Fert. 77, 321-327.

Grubb, P. \& Jewell, P.A. (1973) The rut and the occurrence of oestrus in the Soay sheep on St. Kilda. $J$. Reprod. Fert., Suppl. 19, 491-502.

Hauger, R.L., Karsch, F.J. \& Foster, D.L. (1977) A new concept for control of the estrous cycle of the ewe based on temporal relationships between luteinizing hormone, estradiol and progesterone in peripheral serum and evidence that progesterone inhibits tonic LH secretion. Endocrinology 101, 807-817.

Hinde, R.A. \& Steel, E. (1978) The influence of daylength and male vocalizations on the estrogen-dependent behavior of female canaries and budgerigars, with discussion of data from other species. Adv. Study Behav. 8, 39-73.

Howles, C.M., Craigon, J. \& Haynes, N.B. (1982) Longterm rhythms of testicular volume and plasma prolactin concentrations in rams reared for 3 years in constant photoperiod. J. Reprod. Fert. 65, 439-446.
Karsch, F.J., Dierschke, D.J., Weick, R.F., Yamaji, T., Hotchkiss, J. \& Knobil, E. (1973) Positive and negative feedback control by estrogen of luteinizing hormone secretion in the rhesus monkey. Endocrinology 92, 799-804.

Legan, S.J. \& Karsch, F.J. (1980) Photoperiodic control of seasonal breeding in ewes: modulation of the negative feedback action of estradiol. Biol. Reprod. 23, 1061-1068.

Legan, S.J. \& Karsch, F.J. (1983) Importance of retinal photoreceptors to the photoperiodic control of seasonal breeding in the ewe. Biol. Reprod. 29, 316-325.

Legan, S.J., Karsch, F.J. \& Foster, D.L. (1977) The endocrine control of seasonal reproductive function in the ewe: a marked change in response to the negative feedback action of estradiol on luteinizing hormone secretion. Endocrinology 101, 818-824.

Lincoln, G.A. (1979) Photoperiodic control of seasonal breeding in the ram: participation of the cranial sympathetic nervous system. $J$. Endocr. 82, 135-147.

Lincoln, G.A., Libre, E.A. \& Merriam, G.R. (1989) Longterm reproductive cycles in rams after pinealectomy or superior cervical ganglionectomy. J. Reprod. Fert. 85, 687-704.

Malpaux, B., Robinson, J.E., Brown, M.B. \& Karsch, F.J. (1987) Reproductive refractoriness of the ewe to inductive photoperiod is not caused by inappropriate secretion of melatonin. Biol. Reprod. 36, 1333-1341.

Malpaux, B., Robinson, J.E., Brown, M.B. \& Karsch, F.J (1988) Importance of changing photoperiod and melatonin secretory pattern in determining the length of the breeding season in the Suffolk ewe. J. Reprod. Fert. 83, 461-470.

Martin, G.B., Oldham, C.M. \& Lindsay, D.R. (1980) Increased plasma LH levels in seasonally anovular Merino ewes following the introduction of rams. Anim. Reprod. Sci. 3, 125-132.

Martin, G.B., Scaramuzzi, R.J. \& Lindsay, D.R. (1983) Effect of introduction of rams during the anoestrous season on the pulsatile secretion of LH in ovariectomized ewes. J. Reprod. Fert. 67, 47-55.

McClintock, M.K. (1971) Menstrual synchrony and suppression. Nature, Lond. 229, 244-245.

McClintock, M.K. (1978) Estrous synchrony and its mediation by airborne chemical communication (Rattus norvegicus). Horm. Behav. 10, 264-276.

McComb, K. (1987) Roaring by red deer stags advances the date of oestrus in hinds. Nature, Lond. 330, 648-649.

Niswender, G.D., Midgley, A.R. \& Reichert, L.E., Jr (1968) Radioimmunologic studies with murine, bovine, ovine and porcine luteinizing hormone. In 
Gondadotropins 1968, pp. 299-306. Ed. E. Rosenberg, Geron-X, Los Altos.

Niswender, G.D., Reichert, L.E., Jr, Midgley, A.R. \& Nalbandov, A.V. (1969) Radioimmunoassay for bovine and ovine luteinizing hormone. Endocrinology 84, $1166-1173$.

Oldham, C.M., Martin, G.B. \& Knight, T.W. (1979) Stimulation of seasonally anovular Merino ewes by rams. I. Time from introduction of the rams to the preovulatory LH surge and ovulation. Anim. Reprod. Sci. 1, 283-290.

Poindron, P., Cognie, Y., Gayerie, F., Orgeur, P., Oldham, M. \& Ravault, J. (1980) Changes in gonadotropins and prolactin levels in isolated (seasonally or lactationally) anovular ewes associated with ovulation caused by the introduction of rams. J. Endocr. 85, 481-486.

Robinson, J.E. \& Karsch, F.J. (1984) Refractoriness to inductive day lengths terminates the breeding season of the Suffolk ewe. Biol. Reprod. 31, 656-663.

Robinson, J.E. \& Karsch, F.J. (1988) Timing the breeding season of the ewe: What is the role of daylength? Repr. Nutr. Develop. 28 (2B), 365-374.

Roche, J.F. \& Dxiuk, P.J. (1969) A technique for pinealectomy of the ewe. Am. J. vet. Res. 30, $2031-2035$.

Rowell, T.E. \& Dixson, A.F. (1975) Changes in social organization during the breeding season of wild talapoin monkeys. J. Reprod. Fert. 43, 419-434.

Russell, M.J., Switz, G.M. \& Thompson, K. (1980) Olfactory influences on the human menstrual cycle. Pharmacol. Biochem. Behav. 13, 737-738.

Schwab, X. \& Lott, Y. (1969) Testis growth and regression in starlings (Sturnus vulgaris) as a function of the presence of females. J. exp. Zool. 171, 39-42.
Siegel, S. (1956) In Nonparametric Statistics for the Behavioral Sciences, pp. 116-127, 184-193. McGrawHill Book Co., Inc., New York.

Signoret, J.P. \& Lindsay, D.R. (1982) The male effect in domestic animals: Effect on LH secretion and ovulation-importance of olfactory cues. In Olfaction and Endocrine Regulation, pp. 63-72. Ed. W. Breipohl. IRL Press Ltd, London.

Thomson, A.L. (1950) Factors determining the breeding season of birds: an introductory view. Ibis 92, 173-184.

Turek, F.W. \& Campbell, C.S. (1979) Photoperiodic regulation of neuroendocrine-gonadal activity. Biol. Reprod. 20, 32-50.

Vandenbergh, J.G. (1969) Male odor accelerates female sexual maturation in mice. Endocrinology 84, 658-660.

Vandenbergh, J.G. (1977) Reproductive coordination in the golden hamster: Female influences on the male. Horm. Behav. 9, 264-275.

Wayne, N.L. (1988) Pineal regulation of seasonal breeding in the ewe: interactions of environmental signals with endogenous rhythms. Ph.D. thesis, University of Michigan.

Wayne, N.L., Malpaux, B. \& Karsch, F.J. (1988) How does melatonin code for day length in the ewe: duration of nocturnal melatonin release or coincidence of melatonin with a light-entrained sensitive period? Biol. Reprod. 39, 66-75.

Whitten, W.K. (1956) Modification of the oestrous cycle of the mouse by external stimuli associated with the male. J. Endocr. 13, 399-404.

Received 13 March 1989 